\title{
REFORMA DO PODER JUDICIÁRIO
}

\author{
Rogério MEdeiros GarCIA DE LIMA*
}

\begin{abstract}
"Juizes ou advogados precisam viver o seu tempo. E, para bem vivê-lo. devem esforçar-se por compreendê-lo, a fim de se premunirem contra a tortura do anacronismo, tão mal quanto a do isolamento" (Orlando Gomes, A Crise do Direito).
\end{abstract}

Está prevista para $200+$ a conclusão da tão esperada reforma do Poder Judiciário. Infelizmente, a conjuntura não lhe é favorável. A reforma é brandida como castigo à magistratura, o patíbulo onde a Justiça brasileira será executada para deleite da opinião pública. A festejada cronista política Dora Kramer, conhecedora dos meandros brasilienses, escreveu em sua coluna diária:

Ao longo de 2004, quanto menos polêmicas forem produsidas, melhor. Daí a idéia de iniciar o ano legislativo, em fevereiro, com a chamada agenda positiva, que inclui a ausência total de debates sobre direitos de quem quer que seja. A menos que seja alguém em apuros com a opiniāo pública, como, por exemplo, o Poder Judiciário. Ou os políticos".

O presidente da República Luiz Inácio Lula da Silva, logo no início de seu mandato, afirmou ser preciso abrir a "caixa preta" do Judiciário. O ministro Maurício Corrêa, presidente do Supremo Tribunal Federal, declarou que o chefe do Executivo exibe deslumbramento no exercício do poder. Os ânimos se exaltaram a ponto de terem sido esvaziados os festejos comemorativos dos 175 anos do Supremo Tribunal

* Juiz da $2^{a}$ Vara de Sucessōes e Ausência de Belo Horizonte-MG. Doutor em Direito Administrativo pela UFMG. Membro efetivo do Instituto dos Advogados de Minas Gerais. Professor de cursos de pós-graduação e do curso de graduação em Direito do Unicentro Newton Paiva.

1 KRAMER, Dora. PT Comanda Agenda de 2004. jornal O Tempo. Belo Horizonte. edição de 24 de dezembro de 2003, p. A.4.

R. Dir. Adm.,

Rio de Janeiro, 235: 37-46,

Jan./Mar. 2004 
Federal. Deixaram de comparecer à solenidade o presidente Lula, a maioria dos ministros de Estado e o presidente da Câmara. deputado João Paulo (PT-SP).

Elio Gaspari relata episódio ocorrido há qualse quatro décadas. durante o Regime Militar. No dia 22 de outubro de 1965, o Marechal Costa e Silva, na ocasião ministro da Guera do governo Castello Branco, discursou para tropas do Exército em Itapeva, interior do Estado de São Paulo. Estava presente o Marechal presidente.

Na véspera, o ministro Álvaro Ribeiro da Costa, presidente do Supremo Tribunal Federal condenara a insubordinação dos militares da chamada "linha dura": - Já é tempo de que os militares se compenetrem de que, num regime democrático, não thes cabe o papel de mentores da Nação.

Costa e Silva atirou no seu discurso: - O Exćrcito tem chefe. Näo precisa de lições do Supremo. Disem que o Presidente é politicamente fraco, mas isso näo interessa, pois ele é militarmente forte.

O general Ernesto Geisel, então chefe da Casa Militar, sugeriu a Castello Branco a imediata demissão de Costa e Silva. Não foi ouvido. Anos mais tarde, Geisel comentaria: - Aquilo que aconteceu em Itapeva foi horrivel. ${ }^{3}$

O desenlace todos conhecemos. Costa e Silva fícou fortalecido entre os militares radicais e chegou à Presidência da República. Seu governo foi eternizado pela História por haver editado o AI-5. Dentre outras coisas, o famigerado ato institucional cerceou a atuação do Poder Judiciário, vedando a concessĩo de habeas corpus a favor dos inimigos do regime.

Hoje, o mesmo governo que se diz progressista e tem como Ministro da Justiça o renomado advogado Márcio Thomaz Bastos, critica de modo inconsequiente decisões judiciais proferidas em autos de conflito envolvendo o movimento dos sem-terra. Ives Gandra da Silva Martins comentou o caso do líder sem-terra José Rainha Júnior: ${ }^{4}$

"O que me impressiona é que as autoridades que não se conformaram com a atuação do magistrado, fuzendo visitas de solidariedade à pessoa que desrespeitou a lei e chamando-o de 'de sequilibrado'. são aquelas que só estão no poder porque a lei os assegura na funçũo e são por ela protegidos!

-Em outras palavras, num Estado democrático de Direito, o império da lei é a garantia maior dos cidadãos e dos governantes. Respeitá-la deve ser o desiderato maior do povo e do governo. As autoridades, que devem cumpri-Ia, devem compreender que não podem prestigiar o seu desrespeito, risco de perderem o direito de ser respeitadas.

2 Jornal Folha de São Paulo, edição de 19 de setembro de 2003, p. A-4. O jurista Walter Ceneviva chega a afirmar que o Poder Judiciário está sendo escarnecido pelo Poder Executivo (Falta ama Constituição à Previdência jornal Follha de São Paulo, edição de 22 de novembro de 2003, p. C-2)

3 GASPARI, Elio. A Ditadura Envergonhada. São Paulu: Companhia das Letras, 2002, págs. 271 e 272 .

4 MARTINS. Ives Gandra da Silva. Necessário Equilibrio de Poderes, Jornal do Brasil, edição de 02 de outubro de 2003, seção Opinião. 
"Felizmente, no Brasil, contra esses descompassos ideológico-temperamentais de algumas autoridades, há, ainda, um Poder Judiciário, cuja função é preservar o Direito, as instituiçōes e fazer justiça.

"Não é demais rememorar a história do moleiro que se negou a vender suas terras a Frederico, o Grande. que as queria para aumentar seu palácio. Quando o rei lhe disse que era rei e tudo podia, respondeu-lhe: Majestade, mas ainda há juízes em Berlim. E o rei não insistiu.

"Felizmente, há juízes não só em Berlim. mas também no Brasil!"

A eleição do presidente Lula trouxe muita esperança ao povo brasileiro. No entanto, decorrido um ano de sua posse, parece que o medo continua vencendo a esperança. Há frustração de expectativas nas áreas política, econômica e social.

Isso não é novidade no Brasil. O cientista social francês Michel Debrun, estudioso da política brasileira, vislumbrou indefinida capacidade de auto-reprodução da nossa realidade política (1983:13). Sucedem regimes e governos. mas ressurgem redivivos as mesmas personagens e os mesmo hábitos oligárquicos e patrimonialistas.

Sobre o fim da ditadura Vargas, em 1945, escrevia Pontes de Miranda (1970:6):

"Assim como o 15 de novembro foi parada de força, para que se mudasse o figurante principal sem se mudar o elenco, a ponto de permanecerem, por trás das cortinas, os monarquistas, e volvessem ao governo, o 29 de outubro permitiu que o ditador caísse sem cair a ditadura. À Assembléia Constituinte, concebida e feita em ambiente de convalescença, faltou a inspiração para desligar-se dos seus compromissos com a estruturação presidencialista e com as forças políticas dos Estadosmembros, durante quinze anos alimentadas de oligocracia civil-militar e de monocracia".

Em 1985, ao cabo do Regime Militar a redemocratização gerou grandes expectativas no seio da sociedade brasileira. Esperava-se que a Nova República introduzisse mudanças fundamentais na vida política, econômica e social da Nação. Contudo, registra Eli Diniz (1997:118-119), não conseguimos nos libertar das amarras do passado:

"A frustração dos esforços para construir algo novo, provocada pela volta ao ponto de partida, golpeia fundamente o 'ethos' da transição em seus aspectos mais vitais, relacionados à esperança de libertar-se da antiga ordem. Sobrevêm o desânimo e a gradual expansão do sentimento de impotência, generalizando-se a percepção de que os problemas são insolíveis e as condiçôes que os geraram. eternas e imutáveis. Entre os sinais emitidos pelos novos tempos, sobressai a idéia de que nada adianta a vontade de mudar, pois, quanto mais se tenta, mais tudo permanece como antes. Ascende ao primeiro plano o mito de eterno retorno".

A questão judiciária não foge à regra geral. Há décadas todos reclamam, inclusive os magistrados, da morosidade da Justiça brasileira. Contudo, nada tem sido feito para erradicá-la. As Fazendas Públicas federal, estaduais e municipais são as protagonistas dos processos judiciais. Violador de direitos constitucionais dos cidadãos, contribuintes, servidores públicos e aposentados, o Poder Público responde por mais de $80 \%$ dos processos represados nos diversos tribunais brasileiros. 
O Ministro da Defesa José Viegas comentou recurso judicial interposto pela União contra sentença de juiza federal. A decisão obriga o governo a devolver às famílias corpos de 61 militantes da esquerda desaparecidos e a permitir acaso a todos os documentos existentes sobre a guerrilha do Araguaia. Viegas perguntou ao jornalista a quem concedia entrevista: - Você já viu réu não recorrer? ${ }^{5}$

A alta autoridade republicana ilustra bem o menosprezo que os governos têm para com a Justiça e a paciência dos cidadãos. Até mesmo o senador José Sarney, normalmente cauteloso, extrapolou a prudencia a criticar decisão de outro juiz federal, concedendo liminar em ação popular para obstar a controvertida indicação do Senador Luíz Otávio para o cargo de ministro do Tribunal de Contas da União. O ex-presidente Sarney apresentará projeto de lei ao Senado para que ações populares contra parlamentares federais sejam julgadas pelo Supremo Tribunal Federal."

Assim também procedera Fernando Henrique Cardoso, no apagar das luzes dos seus dois mandatos presidenciais. Sancionou a Lei $n^{\circ} 10.628$, de 24 de dezembro de 2002. dando nova redação ao artigo 84 do Código de Processo Penal e estendendo o foro privilegiado a ex-presidentes da Repúblical e outras gradas autoridades:

"Art. 84. A competência pela prerrogativa de função é do Supremo Tribunal Federal, do Superior Tribunal de Justiça, dos Tribunais Regionais Federais e Tribunais de Justiça dos Estados e do Distrito Federal, relativamente às pessoas que devam responder perante eles por crimes comuns e de responsabilidade.

$\$ 1^{\circ}$ A competencia especial por prerrogativa de função. relativa a atos administrativos do agente, prevalece ainda que o inquérito ou a ação judicial sejam iniciados após a cessação do exercício da função pública.

$\S 2^{\circ}$ A ação de improbidade, aí que trata a Lei $n^{\circ} 8.429$, de 2 de junho de 1992 , será proposta perante o tribunal competente para processar e julgar criminalmente o funcionário ou autoridade na hipótese de prerrogativa de foro em razão do exercício de função pública, observado o disposto no $\$ 1^{\circ "}$.

A favor da constitucionalidade do novel dispositivo, exsurgiu a abalizada opinião de Fernando Tourinho Filho. ${ }^{7}$ Não é o que se infere, contudo, da lição de Hélio Tornaghi (1988:126/127):

"A competência por prerrogativa de função, de que fala o Código de Processo Penal, não sugere o foro privilegiado. A Constituição republicana de 1891 , no $\$ 2^{\circ}$ do art. 72, aboliu os privilégios de nascimento e os foros de nobreza. extinguiu as ordens honorificas e todas as suas prerrogativas e regalias, bem como os títulos nobiliárquicos e de Conselho (...)

"O privilégio refere-se à pessoa: não assim a prerrogativa. Não há foro especial para conde, barão ou duque: não existe acepção de pessoas; a lei não tem preferências nem predileções. Mas leva em conta a dignidade da função, a altitude do cargo. Se

5 Jornal Folha de São Paulo. 09 de setembro de 2003, p. A-8.

6 Jornal Folha de São Paulo, 10 de setembro de 2003, p. A-7.

7 TOURINHO FILHO. Fernando. Da Competência pela Prerrogativa da Função. São Paulo: Revista dos Tribunais, volume 809. março de 2003. págs. 397/410. 
a pessoa deixa de exercê-lo, perde a prerrogativa, que não é sua, mas da função. $O$ entendimento contrário não me parece razoável" (grifos no original).

Isso remonta à era colonial. Athos Gusmão Carneiro (1988:126-127), em vigorosa digressão histórica. recorda que tivemos em nosso País o cargo de juiz conservador da Nação Britânica, criado mediante o Alvará de 04 de maio de 1808 :

"Não se tratava propriamente de um juiz inglês, mas de juíz nacional escolhido pelo súditos ingleses residentes no local da jurisdição, aprovada a escolha pelo embaixador ou ministro da Grä-Bretanha. e levado o nome ao rei lao príncipe regente) que poderia vetá-lo, procedendo-se, então, a nova escolha: Hei por bem crear nesta cidade ham Juiz Conservador para que processe esentenceie as causas que pertencerem à mesma Naçăo, na forma que praticava o Juiz Conservador, que havia em Lisboa'.

"O privilégio foi ratificado pelo art. X do Tratado de Comércio e Navegação fïrmado aos 19 de fevereiro de 1810 entre 'Sua Alteza Real o Príncipe Regente de Portugal', representado pelo Conde de Linhares. Rodrigo de Souza Coutinho, e 'Sua Majestade El-Rei do Reino Unido da Grä-Bretanha e Irlanda', representado por Percy Clinton Sydney, Lorde Visconde e Barão de Strangford".

O Tribunal de Justiça de São Paulo considerou inconstitucional o dispositivo legal, nos autos da Ação Penal nº65.288.0/9-00, em que foi relator o Desembargador Paulo Shintate: ${ }^{\circ}$

"A disposição do $\$ 1$ do art. 84 do Código de Processo Penal, na redação dada pela Lei $n^{\circ}$ 10. 628/2002, é inconstitucional, quer por ter pretendido alterar regras de competência originária do Tribunal de Justiça estabelecidas pela Constituição Estadual, quer por ter pretendido interpretar a norma constitucional, invadindo a competência dos tribunais e violando o principio da independência harmoniosa entre os poderes".

De mais a mais, o artigo $5^{\circ}$ da Constituição Federal de 1988 considera todos iguais perante a lei, sem distinção de qualquer natureza. E a consagração do princípio da isonomia. Lembra Carlos Ari Sundfeld (1997:155) que referido princípio está na base de inúmeras outras normas dispostas no texto constitucional:

"A) do art. 5", 1 , segundo o qual homens e mulheres são iguais em direitos e obrigações'; b) do art. $5^{\circ}, X L I$, segundo o qual 'a lei punirá qualquer discriminação atentatória dos direitos e liberdades fundamentais': c) do art. 37. 'caput', que consagra a 'impessoalidade' como principio da Administraçäo.

"Do conjunto de normas constitucionais, bem assim de seu sentido, extrai-se que os particulares são iguais perante o Estado como um todo. São iguais perante o legislador, assim devendo ser por ele tratados. São iguais perante a lei, donde a necessidade de, em sua aplicação. o juiz como a Administração, tratarem-nos de modo parificado.

"Disso resulta que o princípio da isonomia é essencial a todo direito público" (grifos no original).

8 Acórdão publicado pela Escola Judicial Desembargador Edésio Fernandes, Tribunal de Justiça de Minas Gerais, Diário do Judiciário-MG, 15 de outubro de 2003, págs. 1/3. 
Celso Antônio Bandeira de Mello (1998:10) sustenta que a lei não deve ser fonte de privilégios ou perseguiçöes. mas instrumento regulador da vida social. Necessita tratar equiitativamente todos os cidadãos. Esse é o conteúdo político-ideológico absorvido pelo princípio da isonomia, constante dos textos constitucionais em geral e assimilado pelos sistemas normativos vigentes.

Então se pergunta: para que serve o juiz de primeiro grau? J. J. Calmon de Passos critica a concentração exagerada de poderes nos tribunais. em detrimento dos juízes da primeira instância (1999:109). As liminares concedidas pelos juízes de primeiro grau, segundo legislação editada durante o Regime Militar, poderão ser cassadas pelos presidentes dos tribunais, para "evitar grave lesão à ordem. à saúde, à segurança e à economia públicas" (Lei 4.348, de 26 de junho de 1964). Os requisitos da cassaçâo são conceitos excessivamente vagos." No entanto diversas liminares deferidas contra os açodados procedimentos das privatizações foram cassadas pelas instâncias superiores. Passado o frisson privatizante, o Banco Nacional de Desenvolvimento Econômico e Social (BNDES) levou formidável calote. O governo Lula celebrou questionável acordo para reestatizar empresal privatizada do setor elétrico.

Apesar da reconhecida honorabilidade da imensa maioria dos magistrados brasileiros, essa deferência do Poder Judiciário aos poderes político e econômico enfraquece a própria instituição. Se não se afirma como Poder, ninguém o respeita como tal. Será tratado como mera repartição burocrática.

Antonio di Pietro, que viabilizou a célebre Operação Mãos Limpas na Itália, era juiz de primeiro grau. Precisamos fortalecer a justiça de primeira instância ${ }^{10} \mathrm{e}$ expurgar da realidade brasileira a fábula de George Orwell. segundo a qual alguns são mais iguais do que outros (A Revolução dos Bichos).

A reforma judiciária não deverá descuidar da controvertida questão do provimento dos cargos de magistrados dos tribunais superiores federais e estaduais. No Brasil, não se dá a devida atenção à designação de magistrados para a más alta Corte de Justiça. Diversamente, os norte-americanos têm consciência da importância de que se reveste o ato presidencial. A sabatina dos futuros magistrados. no Senado americano, é acompanhada com fervor pela mídia televisiva e escrita. Os juizes da Suprema Corte dos Estados Unidos têm influido historicamente na evolução das liberdades civis. Questões como escravidão, tributação ilegal, liberdade de expressão, discriminação racial e aborto são decididas por eles. O ex-presidente Nixon sucumbiu

9 De modo semelhante, o Supremo Tribunal Federal e o Superior Tribunal de Justiça proscreveraın a possibilidade de concessão de antecipação de tutela contra a Fazenda Pública, por haver incompatibilidade com o princípio do reexame necessálio (nesse sentido, Superior Tribunal de Justiça, Recurso Especial no 103.752-SP, Min. Edson Vidigal. DJLi 01.02.1999).

10 Louvável a opinião do Ministro Nelson Jobim, do Supremo Tribunal Federal, ato criticar a possibilidade de interposição de inúmeros recursos: "Não se pode ter o primeiro grau apenas como mero coletor de provas" jornal Estado de Minas. Belo Horizonte, edição de 23 de novembro de 2003). 
ao peso do veredito supremo sobre o prosseguimento das investigações do escândalo Watergate.

Aqui, diversamente, as indicações para o Supremo Tribunal Federal não raramente contemplam amigos ou aliados políticos de sucessivos presidentes da República. Salvo honrosas exceções, não se atenta para a relevância do cargo e a missão de defesa da Constituição e do Estado Democrático de Direito. Decisão lapidar foi proferida pelo ministro da Suprema Corte Celso de Mello. nos autos de ação direta de inconstitucionalidade versando a frustrada cobrança de contribuição previdenciária dos inativos, durante o governo do presidente Fernando Henrique Cardoso:

"A DEFESA DA CONSTITUIÇÃO DA REPÚBLICA REPRESENTA O ENCARGO MAIS RELEVANTE DO SUPREMO TRIBUNAL FEDERAL. O Supremo Tribunal Federal que é o guardião da Constituição, por expressa delegação do Poder Constituinte - não pode renunciar ao exercicio desse encargo, pois, se a Suprema Corte falhar no desempenho da gravissima atribuição que the foi outorgada, a integridade do sistema político, a protę̧äo das liberdales piblicas, a estabilidade do ordenamento normativo do Estado, a segurança das relaçós juridicas e a legitimidade das instituiçóes da República restarão profundamente comprometidas. $O$ inaceitável desprezo pela Constituição näo pode comverter-se èm prática governamental consentida. Ao ménos, enquanto houver um Poder Judiciário independente e consciente de sua alta responsabilidade política, social e jurídico-institucional"."

As designações de Ministros do Supremo Tribunal Federal, outrossim, não devem levar em conta fatores econômicos, sociais, políticos ou étnicos. A preocupação maior deverá ser com a escolha de magistrados comprometidos com a defesa inarredável da Constituição e da ordem jurídica vigente.

Ainda recentemente, durante a campanha presidencial de 2002. o então candidato Ciro Gomes dirigiu duras críticas às decisões tomadas pelo Tribunal Superior Eleitoral nos conflitos emergentes daquela disputa política. Partiram do alegado fato de um dos magistrados da Corte, também Ministro do Supremo Tribunal Federal, manter evidentes laços de amizade com o cancliclato governista José Serra.

O provimento de cargos de juízes das cortes superiores, por designação do Poder Executivo, politiza indevidamente o Poder Judiciário. Nas cortes estaduais e federais, as vagas do quinto constitucional, destinadas a advogados e membros do Ministério Público, são providas por ato governamental. A promiscuidade com interesses políticos afetos ao Executivo é maléfica e deverí ser erradicada.

O mesmo se diga em relação ao Ministério Público. A investidura no cargo de Procurador-Geral da República não deveria ser da competência do chefe do Poder Executivo. Para Miguel Reale (1987:105106), nada parece mais absurdo do que o Procurador-Geral da República atuar como longa manus da Presidência da República.

Muitos políticos que hoje criticam acerbamente o Judiciário já foram governadores de Estados. Teriam preenchido os cargos de magistrados dos tribunais de 
justiça mediante quais critérios? Indicavam juristas aliados, neutros ou inimigos políticos? Abstiveram-se de interferir nas designações de juízes para as cortes federais instaladas nos Estados. inclusive os tribunais regionais eleitorais"?

O assunto é sério e demanda muita reflexão. Precisamos rever os critérios de nomeação de magistrados para os tribunais brasileiros, compatibilizando-os com o Estado Democrático de Direito estabelecido pela Constituição de 1988.

Last but not least, emerge a insolúvel questão dat fixação de critérios objetivos para as promoções por merecimento dos magistrados.

Os juízes constituem classe solidária ou estarão mais preocupados com interesses pessoais imediatos? Na minha tese de doutorado (2002:197) escrevi que a falta de critérios na promoção por merecimento cria o "afilhadismo" entre desembargadores e juizes. Estes últimos necessitava lisonjear frequüentemente os primeiros. Ao nível da primeira instância, o convívio entre juízes não é nada solidánial Verifica-se permanente porfia de vaidades pessoais: é a cultura da rivalidade entre potenciais adversários nas futuras promoçōes.

Maquiavel. em O Príncipe, ensinou que o governante não precisa possuir todas as qualidades recomendíveis a $\mathrm{um}$ chefe de Estado. Bastal que aparente possuí-tas. Os juízes tendem a se tomar maquiavélicos nesse sentido. Mais do que em ter as qualidades do bom magistrado, estarão preocupados em aparentar possuídas. Por exemplo. realizam obras suntuosas em prédios forenses. promovem festas feéricas ou se apegam ao recebimento de comendas e condecorações, em busca de notícias elogiosas na mídia. Muitas vezes a efíciente prestação jurisdicional fica ao largo de tanto aparato.

Eis influência bastante nociva na administração da justiça. Preteridos injustamente em promoções por merecimento, bons magistrados vêem esmorecer o entusiasmo com a carreira e a atividade cotidiana.

Devemos refletir com Eric Hobsbawn (2000:191):

"Se o inico ideal dos homens é a busca da felicidade pessoal, por meio do acúmulo de bens materiais, a humanidade é uma espécie diminuida".

Enfim, quando meia dúzia de juizes lamentavelmente se enveredam pelo caminho da corrup̧̧ão, todos os cerca de quinze mil magistrados brasileiros são indiscriminadamente fustigados. Tomou-se insuportável ser juiz de direito nos tempos atuais. Os magistrados não podem mais frequientar casas de amigos ou parentes. A menos que se sintam confortáveis ao ouvir imprecações contra o Judiciário e os Juízes corruptos".

No entanto, a Justiça brasileira apresenta mazelas encontradiças no âmbito dos demais poderes, como nepotismo e mega-salários pagos a alguns poucos funcionários privilegiados. Ela é o espelho da sociedade brasileira. Não é melhor nem pior do que as instituições em geral.

Sérgio Buarque de Holanda. no clássico Raizes do Brasil (1976:106-107), definiu o brasileiro como "homem cordial". Possui sociabilidade aparente para obter vantagens pessoais e evitar cumprir a lei que o contrarie. É o famoso "jeitinho" brasileiro.

Os mesmos que xingam acerbamente os "juízes corruptos", elegem o prefeito, vereadores e deputados pensando em benesses pessoais. Não idealizam o repre- 
sentante que administrará e elaborará leis em nome dos cidadãos, mas o "amigão" que vai resolver seus problemas: emprego, bolsa de estudo, tratamento médico gratuito, transferência do filho para a universidade pública etc. Vai livrá-los de problemas com o delegado de polícia ou o fiscal de tributos, se possível ajeitando a transferência do "incômodo" funcionário para localidade bem distante.

São os mesmos que sonegam imposto de renda, não fornecem recibo ou nota fiscal a clientes e consumidores e subornam o guarda de trânsito e o fiscal da fazenda. Contudo, somos todos muito bons. Corruptos são os outros.

Não podia ser diferente no âmbito do Judiciário. Um conhecido meu, cidadão muito honesto em sua comunidade, relatou ter contratado determinado advogado porque é juiz aposentado e tem "livre trânsito" no fórum da comarca onde exerce a advocacia.

Com quase quinze anos de magistratura, posso afirmar que os juízes recebem pedidos a todo instante. Qualquer cidadão tem um parente, amigo ou amigo do amigo de um magistrado. Usando esses canais, pede "uma mãozinha" no julgamento do seu processo. Quando o pedido é apenas para agilizar o andamento da causa, poderemos relevar Contudo, o mais das vezes. explícita ou implicitamente, o Jeitinho" almejado é a decisão a seu favor, ainda que contra a lei.

No fundo, no fundo, somos todos iguais.

Referências Bibliográficas

BANDEIRA DE MELLO, Celso Antônio. Conteúdo Jurídico do Principio da Igualdade. São Paulo: Malheiros Editores, $3^{a}$ ed., 1998.

BUARQUE DE HOLANDA, Sérgio. Raízes do Brasil. Rio de Janeiro: Livraria José Olympio Editora, $9^{\text {a }}$ ed., 1976.

CALMON DE PASSOS. J. L. Direito, Poder, Justiça e Processo - Julgando os que Nos Julgam. Rio de Janeiro: Editora Forense, 1999.

CARNEIRO, Athos Gusmão. Jurisdição e Competência. São Paulo: Saraiva, $3^{\text {a }}$ ed., 1988.

CENEVIVA, Walter. Falta uma Constituição à Previdência, jornal Folha de São Paulo, edição de 22 de novembro de 2003, p. C-2.

DEBRUN, Michel. A Conciliação e Outras Estratégias. São Paulo: Brasiliense, 1983.

DINIZ, Eli. Crise, Reforma do Estado e Governabilidade. Rio de Janeiro: Editora Fundação Getúlio Vargas, 1997.

GASPARI, Elio. A Ditadura Envergonhada. São Paulo: Companhia das Letras, 2002.

GOMES, Orlando. A Crise do Direito. São Paulo: Max Limonad, 1955.

HOBSBAWN, Eric. O Novo Século - Entrevista a Antonio Polito. São Paulo: tradução Cláudio Marcondes, Companhia das Letras, 2000.

KRAMEIZ, Dora. PT Comanda Agenda de 2004, jornal O Tempo, Belo Horizonte, edição de 24 de dezembro de 2003, p. A-4.

LIMA, Rogério Medeiros Garcia de. O Direito Administrativo e o Poder Judiciário. Belo Horizonte: Del Rey, 2002. 
MACHIA VELLI, Nicollo. O Príncipe. Rio de Janeiro: Edições de Ouro, trad. Lívio Xavier, sem data.

MARTINS, Ives Gandra da Silva. Necessário Equilibrio de Poderes, Jornal do Brasil, edição de 02 de outubro de 2003, seção Opinião.

PONTES DE MIRANDA. Comentários à Constituição de 1967. São Paulo: Editora RT, Tomo I, $2^{\mathrm{a}}$ ed., 1970.

REALE, Miguel. Liberdade e Democracia. São Paulo: Saraiva, 1987.

SUNDFELD, Carlos Ari, Fundamentos de Direito Público. São Paulo: Malheiros Editores, 1997.

TOURINHO FILHO. Fernando. Da Competência pela Prerrogativa da Função. São Paulo: Revista dos Tribunais, volume 809. março de 2003, págs. 397/410.

TORNAGHI, Hélio. Curso de Processo Penal. São Paulo: Saraiva, volume 1, $5^{a}$ ed., 1988. 